\title{
Article Review - Short Communication on Probiotic Claim Substantiation
}

\author{
Tsukasa Jonathan Tanaka, M.S ${ }^{1,2}$ \\ ${ }^{1}$ Department of Clinical Research, Texila American University, Georgetown, Guyana \\ ${ }^{2}$ Department of Clinical Research, Universidad Central de Nicaragua, Managua, \\ Nicaragua
}

\begin{abstract}
This article review focused on the analysis of the journal article "More Information Needed on Probiotic Supplement Product Labels" by Merenstein et al., 2019, published in the Journal of General Internal Medicine. The aim of such a review was to communicate a short critique as well as highlighting the need for fieldwork in regulatory compliance. Here, the review started with a general summary of the article, but also in conjunction with the literature review that the authors established. This was necessary to understand the article in its field of expertise whilst giving a clearer purpose on the need for more fieldwork of this kind. Without such understanding, it would have been difficult to understand the regulatory compliance of dietary supplement label regulations in the US. Then, a thorough analysis and deconstruction of the articles structure, as well as article critique, were established. The authority of the paper and other topics such as authority, accuracy, relevance, etc., were examined for effectiveness in conveying the research question that the authors were concerned with; that more information may be needed for product labels in probiotic supplements in the US. Lastly, the graphs, tables, and figures were evaluated to make a conclusion about the study as well as a discussion on the recent advances related to the label compliance of probiotic supplements. The paper, albeit was on the shorter side, was effective and was also simple in establishing a need for more information on the label. Thus, more transparency on clinical substantiation is needed.
\end{abstract}

Keywords: Clinical Substantiations, Label Compliance, Probiotics, Review, Regulatory, Short Communication.

\section{Introduction}

The aim of this review is to focus and highlight on the category of dietary supplements, specifically probiotics, in the US in a real retail scenario [1]. Rather than the science of the probiotic itself, the authors of this article that was reviewed examined the regulatory status of probiotic labeling on consumer-packaged goods. Probiotics, according to the FAO/WHO, is a live microorganism that must be administered in adequate amounts that also must confer a health benefit to the host [2].

Here, this could fall under food, dietary supplement, medical foods, therapeutic drugs, biologics, or other regulated categories $[3,4]$. In the US, dietary supplements are subjected to laws and regulations to comply with the Chapter 21 Code of Federal Regulations (CFR) Part 101.9 [3, 4]. However, each dietary supplement categories are not known in detail and does not have enforcement criteria for claim substantiation on the label for audiences to understand easily [5]. This is particularly interesting as each probiotic have a varying degree of claims substantiation in terms of scientific evidence.

Furthermore, it is (although recommended) not necessary to disclose the strain name of the microorganism. Industry-related self-regulation (such as the Council for Responsible Nutrition or $\mathrm{CRN}$ ) have worked together with other industry 
trade associations (such as the International Probiotics Association or IPA) to set a standard for such label compliance legislation.

At times, these legislative efforts could be in the form of "Citizen's Petition" that could later be enacted as a Federal/State Regulation $[1,2]$. This is exactly the case with probiotics supplement labels - more specifically, in the colony-forming units or CFU counts. Currently, the Food and Drug Administration or the US FDA still enforces an archaic "milligram" designation of such probiotics, but the therapeutic dosage is in CFUs [6].

However, as aforementioned, the Citizen's Petition have passed, with the CFU being an acceptable alternative [6]. Unfortunately, there are many probiotic supplements that may not have been informed in the new alternative regulation, let alone label compliance in general $[7,8,9]$. Thus, this article review examined the label compliance and completeness of current probiotic supplements in the US.

\section{Materials and Methods}

\section{Article for Review}

The article that was reviewed is stated in [1].

Here, the material (article) was obtained from the PubMed Database [10].

\section{Analytical Methods}

The article was deconstructed and reviewed for the following content: summary and structure as a background basis for the hardware of the article. The article review was communicated and analyzed on the quality of authority, accuracy, currency, relevance, objectivity, stability, as well as the figures, graphs, and diagrams (Table 1).

The review deconstructions were largely adapted from previous literature for integrative, and a partial systemic approach without the criteria defined $[11,12]$.

Table 1. Details of Article Analysis Criteria

\begin{tabular}{|l|}
\hline Criteria Review \\
\hline Summary \\
\hline Structure \\
\hline Quality of Authors \\
\hline Currency \\
\hline Relevance \\
\hline Objectivity \\
\hline Stability \\
\hline Figures/Graphs/Tables \\
\hline
\end{tabular}

\section{Results}

\section{Article Summary}

This article investigated the label compliance of probiotics, more specifically to determine if probiotics dietary supplements were labeled to support any structure-function claims. The methods were straightforward in that researchers investigated four retail establishments from October 2018 to March 2019 in the US [1]. The authors assessed recommended usage, dosage/serving size, CFUs, storage information, and the genus, species, and strain of the probiotic [1]. These were then reviewed for the claims to have substantiated evidence per strain. The inclusion/exclusion criteria were that at least one study (randomly controlled human) was published on PubMed. Results of the paper showed that 93 products were investigated, and 67 of those seemed to be unique. The results showed that $35 \%$ of the 93 products had evidence for their label claims, 18 guaranteed ends of shelf-life viability, and some had strains per product that were unknown or did not 
support clinical evidence per strain. The article did not assess the safety aspect of the products, but these products generally contained similar genus, species, and strains [1]. Here, the authors concluded that future research in safety and a range of potential benefits should be assessed. The authors also commented that they could help understand the probiotic claim evidence to healthcare practitioners to make meaningful and therapeutic choices [1].

\section{Article Structure}

This article portrayed a common structure in terms of article structure. Albeit a short and simple observational study, this study exhibited a short and concise message for the published findings. The article structure conveyed an Introduction to explain the background, a Methods section to describe exactly what was done, a Results section to illustrate the findings, and a discussion section to analyze the findings. It goes without mentioning, but the other administrative portions such as references and a disclaimer of conflict of interest were also noted and appropriate. The abstract, however, was not found. Although unconventional, the abstract may not be necessary for this observational/survey-type article. This is because the investigation and article were rather on the short side. Therefore, by adding an abstract section may become a redundant section that may not serve the purpose of a summary [1]. However, it would have been beneficial to expand the Introduction section a bit more to allow the readers to understand the background of this research. It also seems as though the literature review (due to the Introduction) may not have been fully explored. On the contrary, the Discussion section very much outlined the limitations of this research and the next steps to validate the findings. The Methods and Results were straightforward with unbiased writings of the facts and, thus, appropriate in structure. The article also explored a bit of regulatory assumptions, of which, gave context to the regional differences around the world for inconsistent findings. Perhaps another "next steps" could have been clearly noted during the discussions and some verification measures. Also, as this was a short communication, a section listing the raw data would have helped illustrate a more meaningful understanding [1]. However, overall, the article structure was appropriate.

\section{Authority}

The authors and journal are of high esteem and very relevant in the fields. Drs. Daniel Merenstein, MD and, Mary Ellen Sanders, Ph.D. are both very prominent scientists in the field where the former is the former President of the International Scientific Association of Probiotics and Prebiotics (ISAPP). ISAPP is a non-profit organization with a global voice on the authority of probiotics and prebiotics in general. John Guzzi, BS, was under the direct supervision of the authors. Thus, they are all credible in the field. The article was published in the Journal of General Internal Medicine, which is the official Journal of the Society of General Internal Medicine. This Journal has been ranked \#1 in Google Scholar H-5 Index and has an impact favor of 4.950 at the time of the review. Here, this is further evidence that the authority and credibility of this paper is not questionable [1].

\section{Accuracy}

The data collection was laid out in detail and not a very complex task for this investigation researchers searched against a database and did a field survey analysis. The statistical methods to obtain the relevant and meaningful comparison were also very straightforward and not too complex. Lastly, the verification of the references was not only current (see below sections) but also not mistuned in terms of article interpretations [1].

\section{Currency}

This article was published in the year of 2019. Here, the years of the references the authors cite range from 2014 to 2018 . The article was 
published in the Journal of General Internal Medicine, as stated above. The Journal is on Volume 35 with Issue number 11 for the year 2020. The article is still being publishing on a current basis. Therefore, this article is current at the time of this article review [1].

\section{Relevance}

The article has verified and validated the theory of what was put as for guidance in regulatory writings. This means that the article has investigated the discrepancies between what was published as a regulation versus what is occurring in "real life". This is relevant to all parties involved- including but not limited to government bodies, researchers, and industry personnel. Also, this article focused primarily on the probiotics sub-category of the dietary supplement regulation. This is particularly relevant as all the data they have collected were of probiotic dietary supplements. Therefore, this article was relevant to such policies [1].

\section{Objectivity}

The information was objectively gathered in the article. The retail products they have investigated were randomly discovered, and the statistical analysis to show the results of such findings were objective as well (no bias in which products). However, the opinion of the authors was biased towards non-big players in the probiotics industry. It seems like the authors have targeted unaware players in terms of regulatory non-compliance on the labels; however, they did not seem to focus solely on the clinical efficacy in terms of substantiation for those that were big players in the industry. Furthermore, the conflict of interest did exhibit financial (and personal to an extent) for certain and specific big players in the industry $[1,13]$.

\section{Stability}

This article, as mentioned in the above sections, was published in the Journal of General Internal Medicine. The article is in the Springer Publishing Group, and the 2019 download rate was roughly 1.49 million downloads in the Journal of General Internal Medicine. Also, ISAPP is a stable Trade Association, and the University that the first author is associated with is a very reputable stable company [1].

\section{Analysis of Figures, Graphs, Diagrams}

This article had two major figures which showed the information gathered from the labels of samples of probiotics obtained at four retail outlets and the number of strains per product with and without evidence. These two graphs (figures) were very straightforward and visualized the results in a way many people could understand. These graphs were dot-graphs and simple bar graphs. The results paved the way to such easy and simple graphs to show the data as complex statistics were not needed. However, it would have been better to title such graphs as well. This is because the descriptions were quite wordy, and most of such descriptions could have been mitigated by the title of the figures [1].

\section{Discussion}

Recent advances to this topic are mirroring a five-fingered sloth. It is very slow. Partly due to the COVID-19 situation. But the regulations, enforcement, and definitions of such clinical substantiation is still in the grey area [14]. Only until recently, with the Bayer vs. FTC case, the Federal Trade Commissioner gave their insight into what is a sound clinical substantiation [15]. However, this was deemed too excessive via industry. We still do not see too many designations or strain-specific regulations that come about. However, there are numerous studies of probiotics efficacy that is being published with new clinical efficacies on the rise $[16,17,18,19]$. Thus, it would be necessary to understand the strain-specific guidance on clinical substantiation. Furthermore, the food and dietary supplements database for legal probiotics are still not as enforced/published as therapeutics. It would be thus interesting to investigate compliance vs what is occurring in "Real life" further. Another relevance to this 
topic is the CFU count or the dosage. Probiotic enumeration methods are plenty, but will there be any differences within methodologies? Let alone intra-variabilities in terms of technique levels? As technologies evolve, there are many pros and cons per methodologies. For example, a brick-and-mortar cell count could be very easy to do and reproducible; however, it may only show a snapshot of the global probiotic's enumeration methods. On the other hand, certain species need to be species and even strainspecific in terms of enumeration methods. If the field cannot expand not these detailed verification and validation procedures, then it would become more evident for the need of a database or monograph that can be enforceable, such as Health Canada has [20].

However, it would be delicate negotiation between transparency and proprietary information. Nonetheless, it would become beneficial if there is a bare understanding and registration of such products at the enforcement level as it seems as though there are too many variables for standards on probiotics as dietary supplements on the finished product and consumer goods side, albeit, at least on the safety of the products initially [21, 22].

\section{Conclusion}

This review summarized and critically dissected the article plot but also the format as well. Here, the article seemingly was on the

\section{References}

[1] Merenstein, D., Guzzi, J., \& Sanders, M. E. 2019. More information is needed on probiotic supplement product labels. Journal of general internal medicine, 34(12),

2735-2737.

https://link.springer.com/article/10.1007/s11606019-05077-5.

[2] Hill, C., Guarner, F., Reid, G., Gibson, G.R., Merenstein, D.J., Pot, B., Morelli, L., Canani, R.B., Flint, H.J., Salminen, S. and Calder, P.C., 2014. Expert consensus document: The International Scientific Association for Probiotics and Prebiotics shorter side with only four pages of narratives and two figures.

However, these articles vary widely in terms of investigations, and, also the topic and field of study as well. Again, although short, this article showed a direct concise need for further validating the label versus substantiation. The article did seem a bit biased in terms of tonality of the article for criticizing non-compliance, but it could very well be a situation of ignorance. Also, the article did not have an abstract, but this was justified indirectly. The simpleness of this investigation resulted in a simple but very dynamic paper that conveyed the message perfectly. If one can follow up on the details of the next steps, that would further verify and validate the need for such uniformity of clinical substantiation being practiced via regulatory guidance. Thus, this article did a great job showing and illustrating the message in an easyto-understand methods.

\section{Acknowledgement}

The author would like to thank his advisors and guides that have helped acknowledge this survey.

\section{Conflict of Interest}

There is no conflict of interest with the author besides the independent employment of a probiotic manufacturer.

consensus statement on the scope and appropriate use of the term probiotic. Nature reviews Gastroenterology \& hepatology.

[3] Food \& Drug Administration (FDA). 2020a. Dietary Supplements. Retrieved November 19th, 2020. https://www.fda.gov/consumers/consumerupdates/dietary-supplements.

[4] Food \& Drug Administration (FDA). 2020 b. Dietary Supplements 101. Retrieved November 19th, 2020. https://www.fda.gov/consumers/consumerupdates/dietary-supplements. 
[5] Degnan, F.H., 2008. The US Food and Drug Administration and probiotics: regulatory categorization. Clinical infectious diseases, 46 (Supplement_2), pp. S133-S136.

[6] Food \& Drug Administration (FDA). 2020c. Policy Regarding Quantitative Labeling of Dietary Supplements Containing Live Microbials: Guidance for Industry. Retrieved November 19th, 2020. https://www.fda.gov/media/115730/download.

[7] Cohen, P.A., 2018. Probiotic safety-no guarantees. JAMA internal medicine, 178(12), pp.1577-1578.

[8] Dailey, Z., Sanders, M.E. and Merenstein, D., 2020. Retail refrigerated probiotic foods and their association with evidence of health benefits. Beneficial microbes, 11(2), pp.131-133.

[9] Gibson, G.R., Hutkins, R., Sanders, M.E., Prescott, S.L., Reimer, R.A., Salminen, S.J., Scott, K., Stanton, C., Swanson, K.S., Cani, P.D. and Verbeke, K., 2017. Expert consensus document: The International Scientific Association for Probiotics and Prebiotics (ISAPP) consensus statement on the definition and scope of prebiotics. Nature Reviews Gastroenterology \& hepatology, 14(8), pp.491-502. [10] Scherer, R.W., Huynh, L., Ervin, A.M., Taylor, J. and Dickersin, K., 2013. Clinical Trials. Gov registration can supplement the information in abstracts for systematic reviews: a comparison study. BMC medical research methodology, 13(1), pp.1-9.

[11]Souza, M.T.D., Silva, M.D.D. and Carvalho, R.D., 2010. Integrative review: what is it? How to do it? Einstein (São Paulo), 8, pp.102-106.

[12] Harris, J.D., Quatman, C.E., Manring, M.M., Siston, R.A. and Flanigan, D.C., 2014. How to write a systematic review. The American Journal of sports medicine, 42(11), pp.2761-2768.

[13] Williams, N.T., 2010. Probiotics. American Journal of Health-System Pharmacy, 67(6), pp.449458.

[14]Food \& Drug Administration (FDA). 2020c. Good Clinical Practices. Retrieved September 13th, 2020. https://www.fda.gov/ScienceResearch.
[15] Saldanha, L.G., 2008. US Food and Drug Administration regulations governing label claims for food products, including probiotics. Clinical infectious diseases, 46 (Supplement_2), pp. S119S121.

[16]Freedman, S.B., Williamson-Urquhart, S., Farion, K.J., Gouin, S., Willan, A.R., Poonai, N., Hurley, K., Sherman, P.M., Finkelstein, Y., Lee, B.E., and Pang, X.L., 2018. Multicenter trial of a combination probiotic for children with gastroenteritis. New England Journal of Medicine, 379(21), pp.2015-2026.

[17] Goldenberg, J.Z., Yap, C., Lytvyn, L., Lo, C.K.F., Beardsley, J., Mertz, D. and Johnston, B.C., 2017. Probiotics for the prevention of Clostridium difficile-associated diarrhea in adults and children. Cochrane Database of Systematic Reviews, (12).

[18] Isolauri, E., Salminen, S. and Ouwehand, A.C., 2004. Probiotics. Best practice \& research Clinical gastroenterology, 18(2), pp.299-313.

[19] Sung, V., D’Amico, F., Cabana, M.D., Chau, K., Koren, G., Savino, F., Szajewska, H., Deshpande, G., Dupont, C., Indrio, F. and Mentula, S., 2018. Lactobacillus reuteri to treat infant colic: a metaanalysis. Pediatrics, 141(1).

[20] Health Canada. 2020. Compendium of Monographs. Retrieved December $14^{\text {th }}, 2020$. https://www.canada.ca/en/health-

canada/services/drugs-health-products/natural-nonprescription/applications-submissions/productlicensing/compendium-monographs.html. [21] Sanders, M.E., Akkermans, L.M., Haller, D., Hammerman, C., Heimbach, J.T., Hörmannsperger, G. and Huys, G., 2010. Safety assessment of probiotics for human use. Gut microbes, 1(3), pp.164185.

[22] Snydman, D.R., 2008. The safety of probiotics. Clinical infectious diseases, 46(Supplement_2), pp. S104-S111. 